\title{
EFFECTS OF STAND-LEVEL DISTURBANCES ON THE SPATIAL DISTRIBUTION OF A LICHEN INDICATOR
}

\author{
J. M. KalwiJ, ${ }^{1}$ H. H. Wagner, And C. Scheidegger \\ Swiss Federal Research Institute WSL, Zuercherstrasse 111, CH-8903 Birmensdorf, Switzerland
}

\begin{abstract}
Due to its assumed dispersal limitation and susceptibility to disturbance, the epiphytic lichen Lobaria pulmonaria is used as an indicator of undisturbed forest stands. The hypothesis was tested that stand-level disturbances have a long-lasting negative impact on the occurrence of L. pulmonaria. Two 19th century stand-level disturbances were reconstructed using aerial photographs from 1933. For 7769 potential host trees within a random sample of 251 plots of 1 ha, the presence of L. pulmonaria, tree species, and diameter at breast height were recorded. An analysis of variance showed that neither historical stand-level disturbances nor current grazing reduced the proportion of colonized trees. Spatial analysis at the tree level revealed a patchy distribution of colonized trees, suggesting L. pulmonaria colonization from nearby sources. Spatial analysis at plot level even showed a positive spatial association of $L$. pulmonaria with historic disturbances. We conclude that the presence of $L$. pulmonaria may provide information about conservation value of a landscape, but not necessarily at a forest stand scale. Although indicator species, such as L. pulmonaria, may be an efficien means to assess the conservation value of a forest, spatially and temporally explicit knowledge of the species' life history characteristics is indispensable in order to prevent possible misinterpretation of ecological processes that the indicator aims to unravel.
\end{abstract}

Key words: Acer pseudoplatanus; ecological continuity; epiphytic lichen; indicator; Lobaria pulmonaria; old growth; spatial analysis; SADIE.

\section{INTRODUCTION}

A high conservation value of forests is generally achieved, and can persist over long time spans, when all successional stages are simultaneously and continuously present (Lindenmayer et al. 2000). In such forests, stands typically originate through natural succession, with a significan proportion of old trees, oldgrowth microhabitats, and a high degree of patchiness and heterogeneity (Hendrickson 2003). Old-growth forest species have common, yet very specific life history traits such as the ability to establish and persist in old-growth associated microhabitats only (Rolstad et al. 2002). Consequently, the presence of such oldgrowth related species could distinguish undisturbed ecosystems from more recently established habitats that have endured a break in the continuity of the ecosystem. Long-term undisturbed habitats are thereby define as habitats with a high ecological continuity (Gauslaa 1994, Kuusinen 1996, Sillett et al. 2000).

The current perception of ecological continuity suggests that the persisting effect of a disturbance event can be verifie by the lack of indicator species (Rose 1976). If an indicator species is dispersal limited, it would take longer for the species to restore the pop-

Manuscript received 17 December 2004; revised 23 March 2005; accepted 30 March 2005. Corresponding Editor: J. Belnap.

${ }^{1}$ Present address: Stellenbosch University, Department of Entomology, Private Bag X1, Matieland 7602 South Africa. E-mail: kalwij@sun.ac.za ulation to the level prior to the disturbance than it would for the habitat to recover. Here, however, scale is important even for poor colonizers, as the distance between disturbed and undisturbed areas determines the usefulness of the indicator species (Peterken 1974). Therefore it is necessary to know how long and to what extent disturbance events affect the distribution of a dispersal-limited indicator species.

Many lichenological studies have correlated indicators of ecological continuity with forest stand age (Rose 1976, 1992, Kuusinen 1996, McCune et al. 2000), forest connectivity (Esseen and Renhorn 1998), or stand-level disturbance events (Boudreault et al. 2000). However, the concept of ecological continuity has been criticized as incomplete, with recent studies (e.g., Norden and Appelqvist 2001, Rolstad et al. 2002) criticizing the lack of operational definition (e.g., on dispersal ability, or on the temporal and spatial scaling of processes involved). The impact of historical disturbance events on the abundance of indicator species of ecological continuity is often anecdotal and can sometimes be related to other variables, such as environmental or geographic gradients (Norden and Appelqvist 2001, Rolstad et al. 2002). Therefore, the dependence on old-growth microhabitats and the dispersal ability of indicator species as well as fragmentation and the stand history of forests need to be clearly define when assessing the ecological continuity of a forest stand. 
The epiphytic lichen Lobaria pulmonaria (L.) Hoffm. is, due to its assumed limited dispersal ability (Walser 2004), one of the most commonly used species to indicate ecological continuity (Rose 1976, Lesica et al. 1991, Gauslaa 1994, Selva 1994, Kuusinen 1996, Sillett et al. 2000). Like many other lichens, L. pulmonaria can reproduce asexually in the form of relatively large vegetative soredia (diaspore of algal cells enveloped by the fungal symbiont) or isidioid soredia (elongated outgrowths from the soralia that break off for dispersal) and sexually by means of ascospores, which are formed in a later stage of thallus development (Denison 2003). Under Central European conditions $L$. pulmonaria thalli need to be about 20 years of age before a reasonable amount of soredia starts being produced (Scheidegger et al. 1997). These vegetative soredia are not likely to disperse as far as ascospores (Levin et al. 2003) owing to their larger size. Since we know that soredia production is poor in younger stands (Hilmo 2002) and that successful establishment of vegetative propagules is positively correlated with host tree diameter at breast height (Riiali et al. 2001), it seems plausible that a stand-level disturbance event would have a persisting effect on L. pulmonaria.

Another argument supporting the indicator value of L. pulmonaria is its sensitivity to changes in the habitat; a sudden exposure of the thallus to high light intensity (e.g., following logging of a forest stand) has been shown to cause permanent light damage (Gauslaa and Solhaug 1996, Gauslaa et al. 2001). However, a transplantation experiment by Hazell and Gustafsson (1999) showed that the lichen can survive on trees retained after logging of a forest stand, and that the location of the thallus on the host tree stem is a more important factor determining survival of the lichen than being sheltered by surrounding trees. Surviving thalli could increase the recolonization rate, which would lower the indicative value for absence of disturbance. Since dispersal limitation as well as sensitivity of $L$. pulmonaria to disturbance is disputed, testing the validity of $L$. pulmonaria as an indicator of stand-level disturbance events may clarify if and how this species can be an indicator of ecological continuity.

This study investigates how the spatial distribution of the epiphytic lichen L. pulmonaria is related to different disturbances within a landscape, where a remarkably high but patchy abundance was noted (Stofer et al. 2004). Since tracking of recolonization in disturbance experiments would take too long, a retrospective approach was adopted to test the validity of L. pulmonaria as an indicator of disturbance events at a stand level. Disturbances in the study area comprise present cattle grazing and two historic stand-level disturbances. We hypothesize that these disturbance events lead to a low density of host trees colonized by L. pulmonaria, while absence of such events results in high densities of colonized host trees. To test this hypothesis we quantifie and compared the spatial as- sociation of L. pulmonaria and its potential host trees with reconstructed stand-level disturbance events within and among 1-ha observation units. We also discuss the validity of L. pulmonaria to assess forest conservation value and as an indicator of ecological continuity at different spatial scales.

\section{Materials And Methods}

\section{Study site}

The study area is part of the Parc Jurassien Vaudois (PJV) in Switzerland, located between $46^{\circ} 28^{\prime}-34^{\prime} \mathrm{N}$ and $06^{\circ} 06^{\prime}-16^{\prime} \mathrm{E}$ at an elevation of $1300-1450 \mathrm{~m}$ (Fig 1a). The PJV is a sylvopastoral landscape, characterized by forests dominated by Norway spruce (Picea abies (L.) Karst.) and pastures on carstic limestone bedrock (Vittoz 1998). The area has relatively few, unevenly distributed host trees (sycamore maple, Acer pseudoplatanus L., and beech, Fagus sylvatica L.) of L. pulmonaria. The fiel data were collected in the northern part of the PJV in 2003. This area comprised 1316 ha, $41 \%$ of which was grazed at that time. Lowimpact logging was employed throughout the area, which encompassed selective logging of trees of all size classes in quantities less than or as high as the annual growth in order to maintain an uneven-aged forest (Schütz 2002).

\section{Field data}

The perimeters of the forest patches were retrieved from an existing Boolean forest map (1:25 000; Swisstopo, Swiss Federal Offic of Topography, Wabern, Switzerland). Circular non-overlapping plots of 1 ha $(N=251)$ were positioned randomly within the forest area of the study area (Fig. 1a). Within each plot, the location of each sycamore maple and beech with a diameter at breast height (dbh) of at least $10 \mathrm{~cm}$ was mapped using a handheld GPS device (Garmin12XL with external antenna; Garmin, Romsey, Hampshire, UK). Lobaria pulmonaria can occur in the canopy or on the stem of a host tree, but was never observed exclusively in a canopy in this survey. Therefore sampling concentrated on host tree stems. Presence or absence of L. pulmonaria and the dbh (classes: $1=10$ $12.5 \mathrm{~cm}, 2=12.5-17.5 \mathrm{~cm}, 3=17.5-22.5 \mathrm{~cm}, 4=$ $22.5-27.5 \mathrm{~cm}, 5=27.5-32.5 \mathrm{~cm}$, or $6=>32.5 \mathrm{~cm})$ were recorded for each mapped tree $(N=7769)$.

\section{Present tree cover}

LiDAR (Light Detection and Radar) data were used to assess tree canopy cover. Two sets of airborne LiDAR data, obtained in summer 2003 by Swisstopo, were used to construct a digital surface model and a digital terrain model. The firs data set consisted of firs returns; representing maximum height with vegetation ( $\sim 10000$ points/ha). The second, filtere data set consisted of returns representing height of terrain without vegetation (i.e., where vegetation was sparse enough 


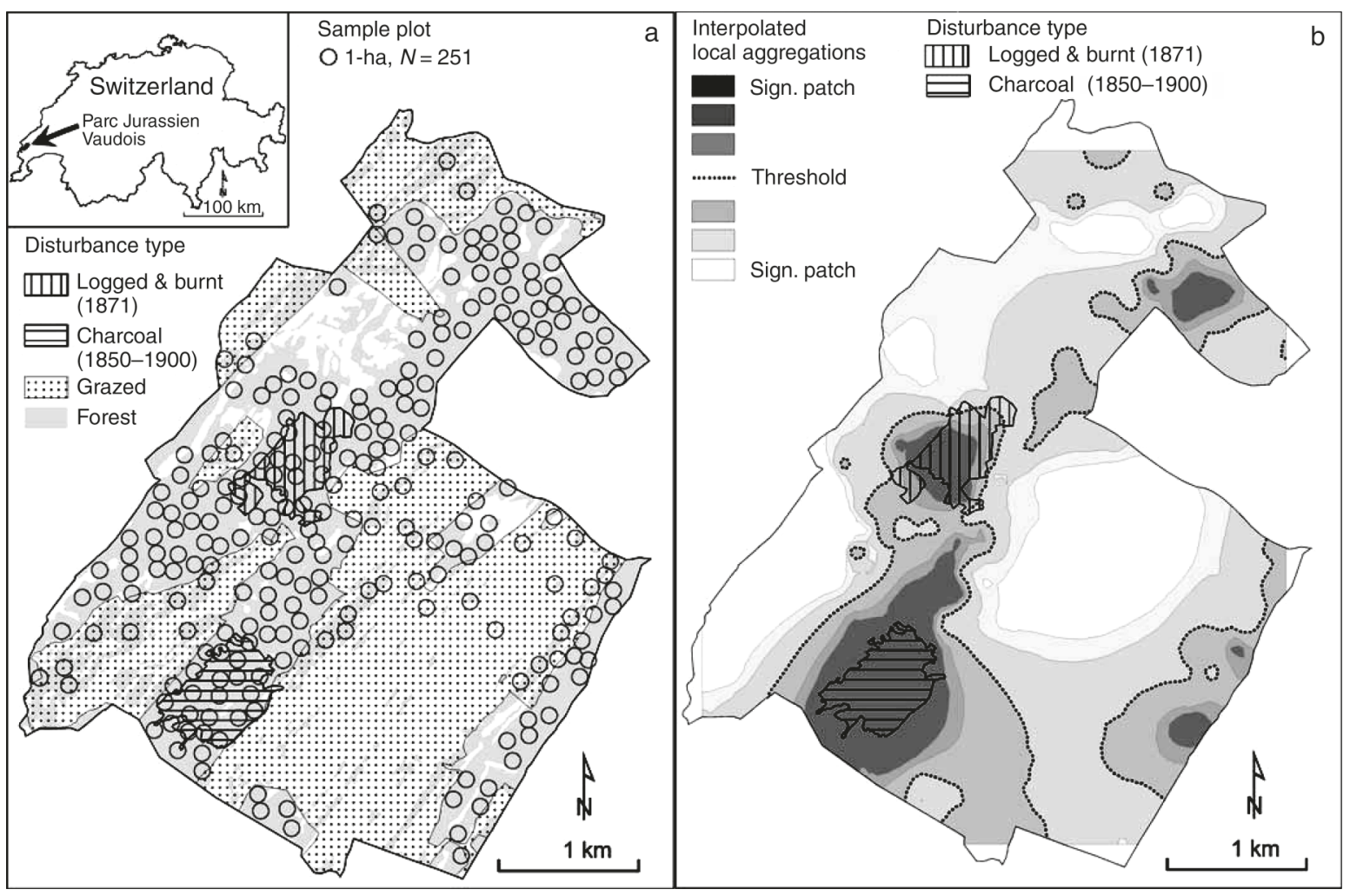

FIG. 1. Stand-level disturbances within the study area and (a) location of sample plots, forest, and grazed areas (Swisstopo Pixelmap 25, 2004), and (b) interpolated distribution of the lichen indicator Lobaria pulmonaria. Dark shaded areas represent patches of local aggregation, while lighter shaded areas represent gaps.

for pulses to reach the ground). Both sets were interpolated by generating triangular irregular networks and subsequent conversion into grids of $0.5 \mathrm{~m}$ using ArcGIS 8.3 (ESRI 2002). Height difference between the two digital models was used as an estimation of vegetation height. Canopy cover data was calculated from the percentage of vegetation exceeding $1.5 \mathrm{~m}$ and included as covariable in the data analysis.

\section{Local forest structure changes}

Change in local forest structure at a 1-ha scale was assessed by a comparison of black-and-white aerial photographs of 1933 with panchromatic orthophotos of 1998 (SWISSIMAGE), all acquired from Swisstopo. The photographs from 1933 were digitized, georeferenced, and orthorectifie in IMAGINE OrthoBASE 8.6 (Leica-Geosystems GIS and Mapping, Atlanta, Georgia, USA), using a digital elevation model with a cell size of $25 \mathrm{~m}$ (DEM25, Swisstopo), and resampled to match the $0.5 \mathrm{~m}$ nominal ground resolution of the 1998 orthophotos. For each 1-ha plot the canopy changes during the period from 1933 to 1998 were assessed visually: (a) decrease of canopy cover and/or tree density $(N=41)$, (b) no distinct changes $(N=147)$, and (c) increase of canopy cover and/or tree density $(N=$ 63).

\section{Stand-level disturbance events}

Two stand-level disturbances were known for stands within the study area (Fig. 1): (a) intensive logging between 1850 and 1900 for charcoal production (B. Pichon, Swiss Forestry Service, personal communication), and (b) intensive logging in 1870 , followed by wind throw and, in the following year, a two-week fir (Rochat 1995). The perimeters of the areas "Charcoal 1850-1900" ( 36 ha) and "Logged \& burnt 1871" ( $\sim 31 \mathrm{ha})$ were delineated from stereoscopic analysis of the orthophotos of 1933. The reconstructed perimeter and intensity of the 1871 stand-level disturbance was validated and refine in a dendroecological study (J. Bolli, J. M. Kalwij, H. H. Wagner, P. Cherubini, C. Scheidegger, and A. Rigling, unpublished manuscript). Youth growth patterns of sampled Norway spruces indicated an open area after 1871 , confi ming the interpretation of the 1933 aerial photographs.

Edge effects of large-scale stand-level disturbances have been shown to affect local microclimatic conditions and lichen composition (Esseen and Renhorn 1998, Harper and Macdonald 2002). Therefore, plots falling even partially within the perimeters of the standlevel disturbances were considered part of the disturbed area ( $N=24$ for "Charcoal 1850-1900," and $N=21$ 
for "Logged \& burnt 1871"). Since stand structure and abundance of sycamore maple and beech in this landscape are likely to be affected by grazing (Gillet and Gallandat 1996), the perimeters of presently grazed areas were mapped. Plots that had $>50 \%$ of their surface in a grazed area were considered "Grazed" $(N=42)$. Since forest management aimed to minimize the impact of logging and was of the same low intensity throughout the area, remaining plots were labeled "Undisturbed" $(N=164)$.

\section{Data analysis}

All nonspatial analyses were performed in SPSS Version 12.0 (SPSS 2003). Due to the small number of colonized beech trees, beech was excluded from the statistical analyses. Mean number of sycamore maples per hectare plot, $f_{\mathrm{A}}$, number of colonized sycamore maples per hectare plot, $f_{\mathrm{L}}$, and proportion of colonized sycamore maples, $p_{\mathrm{L}}$, for the different disturbance categories "Undisturbed," "Grazed," "Charcoal 18501900," and "Logged \& burnt 1871" were compared by one-way analyses of variance (ANOVA). The ANOVA was based on square-root transformed values for $f_{\mathrm{A}}$ and $f_{\mathrm{L}}$, and on arcsine of the square-root for $p_{\mathrm{L}}$ (Underwood 1997). Due to unequal variances, significanc of the pairwise differences between the disturbance categories was assessed using Tamhane's T2 instead of Bonferroni adjustments (Tamhane 1977), as implemented in SPSS.

A linear regression model was calculated to test the effect of host tree density, $f_{\mathrm{A}}$ (square-root transformed), on colonization proportion, $p_{\mathrm{L}}$ (arcsine square-root transformed), for each of the disturbance categories. One reason L. pulmonaria may not have colonized all plots could be due to dispersal limitation. Therefore, plots without L. pulmonaria were excluded from this analysis.

The effect of dbh class and disturbance category on host tree density, $f_{\mathrm{A}}$ (square-root transformed), and on colonization proportion, $p_{\mathrm{L}}$ (arcsine square-root transformed), per dbh class and plot was tested in separate two-way ANOVA, excluding plots without L. pulmonaria for the analysis of $p_{\mathrm{L}}$. The normally distributed variable "Present tree cover" was used as covariable.

The spatial aggregation of colonized trees was quantifie by determining the distance to nearest colonized neighbor $(\mathrm{NN})$ for each colonized or uncolonized sycamore maple. A three-way ANOVA was used to test for the difference in the mean NN distance (squareroot transformed) between colonized and uncolonized trees accounting for interactions with dbh class, disturbance category, and present tree cover. To avoid edge effects, ANOVA was restricted to sycamore maples closer to a colonized tree than to the edge of their 1-ha plot, and clusters of stems with shared base were excluded $(N=1911)$.

To characterize the spatial association of the tree and lichen species among plots, spatial analysis by distance indices (SADIE) was used to calculate cluster indices and tested for statistical significanc (Perry et al. 1999). For both species, the index of aggregation, I, was define as $D_{\text {obs }} / D_{\text {exp }}$, where $D_{\text {obs }}$ is the minimum distance that individuals are required to move to neighboring plots to obtain a regular distribution, and where $D_{\text {exp }}$ is the same quantificatio under randomized plot distribution. The larger is $I$, the more spatially aggregated is the observed arrangement of counts. For each plot, the following clustering indices were calculated: (a) $I_{\mathrm{A}}$ for the total number of sycamore maples per plot, (b) $I_{\mathrm{L}}$ for the number of colonized sycamore maples, and (c) $I_{\mathrm{D}}$ as a Boolean value for both historical stand-level disturbances. The categorical variable "Local forest structure change" was converted into three Boolean dummy variables to obtain $I_{-}, I_{0}$ and $I_{+}$for "Local decrease," "No change," and "Local increase," respectively.

For each plot $i$ an index of clustering $v_{i}$ was calculated, which measures the degree to which each plot contributes to a cluster of nearby plots of high values (patch) or to a cluster of nearby plots of low values (gap). Local values of $v_{i}$ below -1.5 were interpreted as gaps, while values exceeding 1.5 were interpreted as patches (Perry et al. 1999).

The overall associations, $\chi$, and local spatial associations, $\chi_{i}$, for the individual plots $i$ of the pairwise combinations of cluster indices $I$ were calculated by the SADIE software to determine the local coincidence of variables (Perry and Dixon 2002); coincidence of clusters would result in a large value of local association, $\chi_{i}$. Sample size adjustment for small-scale spatial autocorrelation in both sets of clustering indices in the SADIE software followed the method of Dutilleul (1993). This is a correction of the degrees of freedom, making similar distributional assumptions as a $t$ test without affecting the degree of association. The statistical significanc of overall association, $\chi$, was tested by means of a two-tailed permutation test with a significanc level of $P=0.05$, where the observed $v_{i}$ were permuted among the sample units (Perry et al. 1999).

Since local clustering indices, $v_{i}$, and association values, $\chi_{i}$, are continuous, contour maps were constructed for visual interpretation of the spatial arrangement of patches. A regularized radial basis function was used as an exact deterministic interpolation technique to derive maps of local associations, $v_{i}$, in ArcGIS 8.3 (Johnston et al. 2001).

\section{RESUlts \\ Effect of stand-level disturbance}

Based on the 7769 examined trees, L. pulmonaria showed a strong preference for sycamore maple (0.086 colonized), compared to beech ( 0.004 colonized; Table $1)$. The three one-way ANOVA showed a significan effect of disturbance category on host tree density, $f_{\mathrm{A}}$ $\left(F=7.42_{3,247}, P<0.001\right)$, on density of $L$. pulmonaria 
TABLE 1 . Tree density $\left(f_{\mathrm{A}}\right)$ and lichen density $\left(f_{\mathrm{L}}\right)$ per disturbance category $\left(p_{\mathrm{L}}\right)$.

\begin{tabular}{|c|c|c|c|c|c|c|c|}
\hline & \multirow[b]{2}{*}{$N$} & \multicolumn{2}{|c|}{ Trees (no./ha) $f_{\mathrm{A}}$} & \multicolumn{2}{|c|}{ Lobaria $\left(\right.$ no./ha) $f_{\mathrm{L}}$} & \multicolumn{2}{|c|}{ Colonized, $p_{\mathrm{L}}$} \\
\hline & & Mean & $\mathrm{SE}$ & Mean & $\overline{\mathrm{SE}}$ & Mean & $\mathrm{SE}$ \\
\hline \multicolumn{8}{|l|}{ Sycamore maple } \\
\hline Undisturbed & 164 & $18.7^{\mathrm{a}}$ & 1.6 & $3.1^{\mathrm{a}}$ & 0.5 & $0.086^{\mathrm{a}}$ & 0.013 \\
\hline Grazed & 42 & $4.7^{\mathrm{b}}$ & 1.6 & $0.4^{\mathrm{b}}$ & 0.2 & $0.028^{\mathrm{b}}$ & 0.013 \\
\hline Charcoal & 24 & $93.1^{\mathrm{c}}$ & 5.9 & $11.4^{\mathrm{c}}$ & 4.2 & $0.105^{\mathrm{c}}$ & 0.030 \\
\hline Logged \& burnt & 21 & $26.7^{\mathrm{d}}$ & 3.1 & $5.0^{\mathrm{c}}$ & 0.5 & $0.190^{c}$ & 0.040 \\
\hline Total & 251 & 24.1 & 1.9 & 3.6 & 0.6 & 0.086 & 0.010 \\
\hline \multicolumn{8}{|l|}{ Beech } \\
\hline Undisturbed & 164 & 7.6 & 0.9 & 0.1 & 0.0 & 0.003 & 0.001 \\
\hline Grazed & 42 & 2.0 & 0.6 & 0.0 & 0.0 & 0.003 & 0.003 \\
\hline Charcoal & 24 & 7.7 & 2.3 & 0.0 & 0.0 & 0.007 & 0.007 \\
\hline Logged \& burnt & 21 & 9.3 & 1.4 & 0.1 & 0.1 & 0.006 & 0.005 \\
\hline Total & 251 & 6.8 & 0.7 & 0.1 & 0.0 & 0.004 & 0.001 \\
\hline
\end{tabular}

Notes: Different letters indicate significan pairwise differences for sycamore maple (Acer pseudoplatanus) at the 5\% level using Tamhane's T2 correction for multiple comparisons with unequal variances. The table lists untransformed frequencies for ease of interpretation, whereas the significanc tests were based on an ANOVA of transformed values $\left(f_{\mathrm{A}}\right.$ and $f_{\mathrm{L}}$, square-root transformed; $p_{\mathrm{L}}$, arcsine square-root transformed). $N$ is the number of plots per disturbance category; the beech species is Fagus sylvatica.

trees, $f_{\mathrm{L}}\left(F=8.34_{3,247}, P<0.001\right)$, and on colonization proportion, $p_{\mathrm{L}}\left(F=6.35_{3,247}, P<0.001\right)$. The pairwise comparisons showed significan differences in sycamore maple density, $f_{\mathrm{A}}$, between all disturbance categories. In contrast, the differences in density of L. pulmonaria trees, $f_{\mathrm{L}}$, and in colonization proportion, $p_{\mathrm{L}}$, between the two stand-level disturbances were not significant

No significan correlation was found between sycamore maple density, $f_{\mathrm{A}}$, and colonization proportion, $p_{\mathrm{L}}$, for any of the disturbance categories (undisturbed: $N=61, R^{2}=0.004, P=0.642$; grazed: $N=6, R^{2}=$ $0.098, P=0.493$; charcoal: $N=23, R^{2}=0.15, P=$ 0.061 ; logged \& burnt: $\left.N=16, R^{2}=0.114, P=0.185\right)$.

\section{Effect of host tree population structure}

A two-way ANOVA of $f_{\mathrm{A}}$ revealed a significan interaction between disturbance category and dbh class, but no effect of present tree cover (Table 2). A higher sycamore maple density, $f_{\mathrm{A}}$ was found in both "Charcoal 1850-1900" as well as in "Logged \& burnt 1871 ," for the middle $(12.5-22.5 \mathrm{~cm})$ dbh classes (Fig. 2, upper graphs).

A similar ANOVA of $p_{\mathrm{L}}$ showed strong effects of disturbance and dbh class, but no effect of present tree cover or significan interaction (Table 2). Colonization proportion, $p_{\mathrm{L}}$, increased considerably with increasing dbh (Fig. 2, center graphs).

\section{Spatial aggregation}

At the tree level, a three-way ANOVA of the nearest neighbor (NN) distance showed a highly significan difference in NN between colonized and uncolonized sycamore maples. This difference did not depend on disturbance category nor on dbh class, as all interaction terms were not significan (Table 2, lower section). Colonized trees were located much closer to their nearest colonized neighbor than uncolonized trees (Fig. 2, lower graphs).

At the plot level, a significan spatial aggregation was found for sycamore maples, $I_{\mathrm{A}}$, as well as for colonized host trees, $I_{\mathrm{L}}$ (Table 3 ). The number of sycamore maples per plot, $I_{\mathrm{A}}$, showed significan association with local increase in tree density, $I_{+}$, and with stand-level disturbances, $I_{\mathrm{D}}$. Lobaria pulmonaria, $I_{\mathrm{L}}$, on the other hand was, apart from an obvious association with sycamore maple, significantl associated with local increase, $I_{+}$. Although not significant L. pulmonaria, $I_{\mathrm{L}}$, had the tendency to be associated with disturbance, $I_{\mathrm{D}}$. This near-significan association could be ascribed to the fact that local increase, $I_{+}$, and disturbance, $I_{\mathrm{D}}$, are not independent variables. The map of the interpolated local aggregation values, $X_{\mathrm{L}}$, showed four distinct clusters of L. pulmonaria (Fig. 1b). Two of these clusters largely overlapped with the area of the reconstructed stand-level disturbances.

\section{DISCUSSION}

Within the context of testing indicator species of undisturbed forest stands, we investigated how the spatial distribution of L. pulmonaria was affected by grazing and two historic stand-level disturbances. We assumed that the effect of selective logging of individual trees was limited to the tree level, therefore of minor importance at the stand-level scale and did not adversely affect local clusters of $L$. pulmonaria. Such effects, however, may differ between lichen species and study area (Hedenas and Ericson 2003). Disturbance effects not only depend on the disturbance intensity, spatial extent, and time elapsed since the event, but also on the dispersal ability (Nilsson et al. 2001) and generation time (Caro and O'Doherty 1999) of affected species. We can only interpret the present distribution of L. pulmonaria, and explain why this species is absent 
TABLE 2. Results of a two-way ANOVA of $f_{\mathrm{A}}$ and $p_{\mathrm{L}}$ as dependent on disturbance category and dbh class, and of a three-way ANOVA of nearest neighbor (NN) distance as dependent on disturbance category, dbh class, and presence of Lobaria pulmonaria.

\begin{tabular}{|c|c|c|c|c|}
\hline Variable & SS & df & $F$ & $P$ \\
\hline \multicolumn{5}{|l|}{ Host tree density, $f_{\mathrm{A}}$} \\
\hline Model & 753.7 & 22 & 34.26 & $<0.0001$ \\
\hline Intercept & 114.3 & 1 & 124.40 & $<0.0001$ \\
\hline Present tree cover & 0.4 & 1 & 0.48 & 0.490 \\
\hline Disturbance & 271.4 & 3 & 98.44 & $<0.0001$ \\
\hline $\mathrm{dbh}$ & 197.0 & 5 & 42.88 & $<0.0001$ \\
\hline Disturbance $\times \mathrm{dbh}$ & 144.6 & 13 & 11.13 & $<0.0001$ \\
\hline Error & 736.9 & 802 & & \\
\hline Total & 6056.0 & 825 & & \\
\hline \multicolumn{5}{|l|}{ Colonized proportion, $p_{\mathrm{L}}$} \\
\hline Model & 25.2 & 22 & 6.16 & $<0.0001$ \\
\hline Intercept & 0.6 & 1 & 3.27 & 0.071 \\
\hline Present tree cover & 0.2 & 1 & 1.20 & 0.275 \\
\hline Disturbance & 3.4 & 3 & 6.15 & $<0.0001$ \\
\hline dbh & 7.4 & 5 & 7.98 & $<0.0001$ \\
\hline Disturbance $\times \mathrm{dbh}$ & 3.1 & 13 & 1.27 & 0.227 \\
\hline Error & 90.9 & 489 & & \\
\hline Total & 204.8 & 512 & & \\
\hline \multicolumn{5}{|l|}{ Nearest neighbor $(\mathrm{NN})$ distance } \\
\hline Model & 426.7 & 35 & 8.38 & $<0.0001$ \\
\hline Intercept & 1671.8 & 1 & 1148.73 & $<0.0001$ \\
\hline Disturbance & 3.7 & 3 & 0.84 & 0.474 \\
\hline $\mathrm{dbh}$ & 3.6 & 5 & 0.49 & 0.782 \\
\hline Lobaria & 119.1 & 1 & 81.84 & $<0.0001$ \\
\hline Disturbance $\times \mathrm{dbh}$ & 11.6 & 11 & 0.73 & 0.715 \\
\hline Disturbance $\times$ Lobaria & 1.7 & 2 & 0.58 & 0.560 \\
\hline Lobaria $\times$ dbh & 12.5 & 5 & 1.72 & 0.128 \\
\hline Disturbance $\times \mathrm{dbh} \times$ Lobaria & 5.6 & 8 & 0.48 & 0.869 \\
\hline Error & 2728.9 & 1875 & & \\
\hline Total & 26804.4 & 1911 & & \\
\hline
\end{tabular}

Note: Models were corrected for unequal sample sizes.

in seemingly suitable habitats, when we know its dispersal abilities. A complicating factor that determines the distribution of L. pulmonaria is its dependence on appropriate host trees, which may at times be scarce themselves. Therefore, we must discuss the distribution of host trees before interpreting effect of disturbances on L. pulmonaria. The spatial association between $L$. pulmonaria and stand-level disturbances was used to test the hypothesis that an absence or lower density of indicator species demonstrates disturbance of a forest stand.

\section{Presence of potential host trees}

Sycamore maple in this study area was described as a species profitin from temporally enhanced light conditions, such as gap dynamics related to succession in natural forests (Vittoz 1998). Cattle substantially reduced the abundance of sycamore maple in grazed areas. Conversely, our distribution data showed that stand-level disturbances led to high densities of sycamore maples (Table 1), irrespective of present tree cover (Table 2). Significantl higher density of sycamore maple, $f_{\mathrm{A}}$, and number of colonized sycamore maple, $f_{\mathrm{L}}$, in the historically disturbed plots suggest that colonization proportion, $p_{\mathrm{L}}$, might be correlated with host tree density, which would imply rapid colonization following host tree expansion. However, no significan correlation was found between sycamore maple density, $f_{\mathrm{A}}$, and colonization proportion, $p_{\mathrm{L}}$, for any of the disturbance categories. Instead, the chance for colonization of sycamore maple seemed to increase in time, as the strong increase in the proportion of colonized trees, $p_{\mathrm{L}}$, with dbh class suggests. A similar effect was described for L. pulmonaria on aspen (Kuusinen 1996) and for other epiphytic species (Hazell et al. 1998, Rolstad and Rolstad 1999). This could be explained by a combination of potential causes. Growth of $L$. pulmonaria can be slow in some habitats (Scheidegger 1995). Individual thalli may persist for decades ( $\mathrm{Gu}$ et al. 2001), which would mean that once a lichen is established, a population may persist as long as the host tree continues to exist. As thick trees are usually older and provide more trunk surface than thin trees, the cumulative probability of colonization is higher (Riiali et al. 2001). Furthermore, the bark of large, old trees is usually rougher, providing favorable environmental conditions regarding humidity (Barkman 1958) and $\mathrm{pH}$ value (Gustafsson and Eriksson 1995). However, our results suggest that the high number of colonized trees in the historically disturbed areas is due to a high number of trees from the thinner dbh classes (Fig. 2), indicating a dynamic system with continuous dispersal 

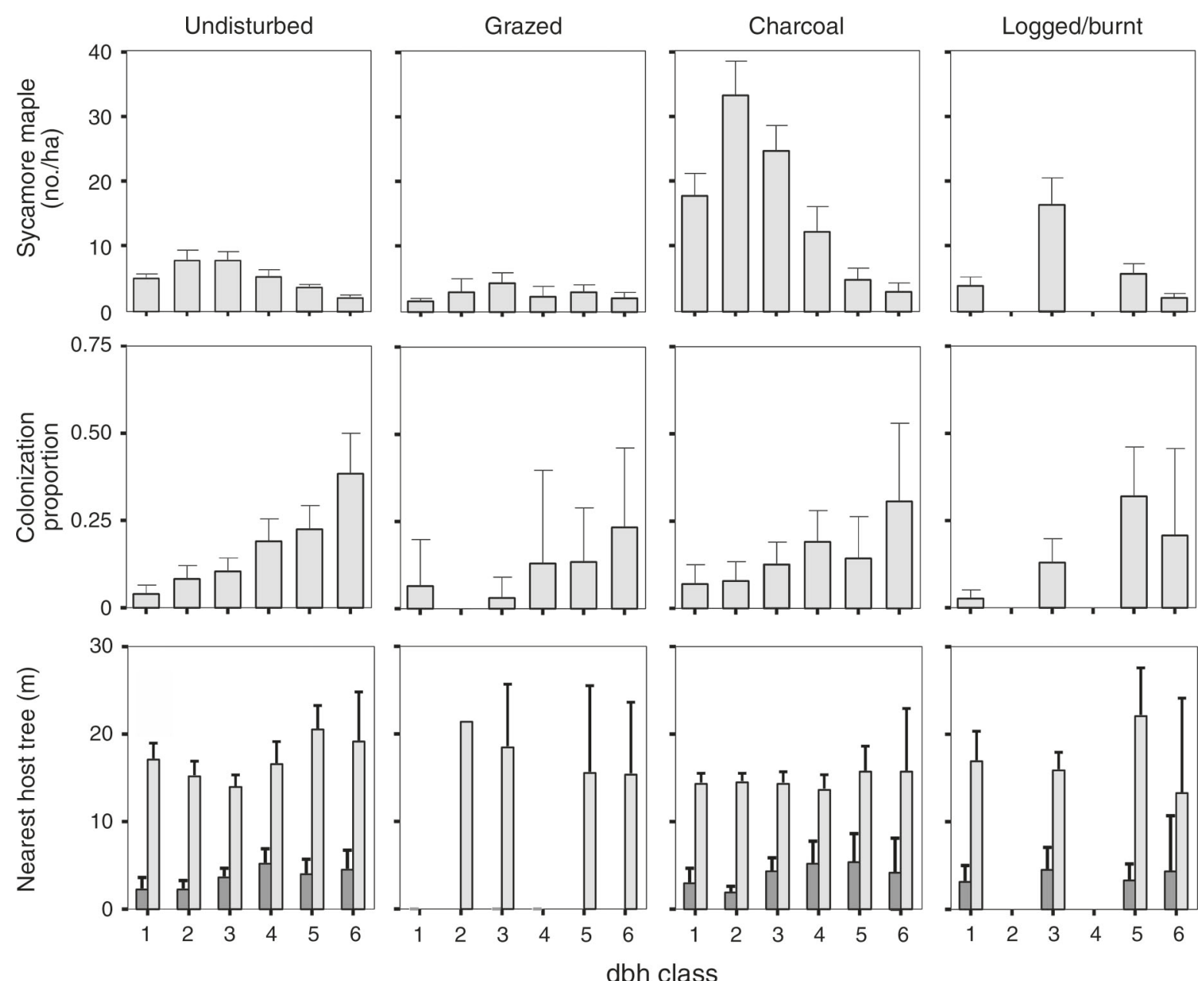

FIG. 2. Sycamore maple density $\left(f_{\mathrm{A}}\right)$, colonization proportion $\left(p_{\mathrm{L}}\right)$ of Lobaria pulmonaria, and distance to the nearest colonized neighbor (NN) for colonized (light gray bars) and uncolonized (dark gray bars) host trees, per dbh class and disturbance category. Values are expressed as mean +2 SE. For ease of interpretation, untransformed values are shown, whereas the significanc tests presented in Table 2 were based on the transformed values.

and colonization (Johansson and Ehrlen 2003). Our results therefore suggest that L. pulmonaria may have profite either from a temporal increase in host tree availability independent of host tree population structure or from increased light conditions during absence of a closed canopy.

Persistence of disturbance effects on L. pulmonaria

Disturbance was hypothesized to result in a lower abundance of L. pulmonaria. However, contrary to our expectation, the distribution of $L$. pulmonaria did not show a negative association with the two stand-level disturbances. The interpolated distribution map of $L$. pulmonaria (b) even suggested that the opposite may be true, although such a trend was not significan (Table 3). Apparently 100-150 years are long enough for both the ecosystem functioning as well as the indicator species to recover to the assumed state prior to the disturbance. Yet, with a high proportion of trees from the intermediate dbh classes especially (Fig. 2), the stand structure of sycamore maple is far from equal to undisturbed areas. Since we also showed that colonized trees are more clustered towards their nearest colonized neighbor than uncolonized trees (Fig. 2), two possible scenarios of recolonization may explain the patchy distribution of L. pulmonaria.

Possibly L. pulmonaria disappeared completely following the disturbances, as would be expected from its sensitivity to permanent light damage (Gauslaa et al. 2001 ) or other sudden changes in microhabitat (Barkman 1958). Recolonization may have occurred by occasional long-distance dispersing diaspores, as Lobaria pulmonaria thalli of identical multilocus genotypes found over distances of $140 \mathrm{~m}$ (Walser 2004) and up to $2 \mathrm{~km}$ (S. Werth, unpublished data) in our study area suggest. This possibility is supported by the occurrence of isolated colonized trees with small dbh in the grazed areas (Fig. 2), suggesting that these trees were rela- 
TABLE 3. Spatial analysis by distance indices (SADIE) of the occurrence of sycamore maple and Lobaria pulmonaria in 251 circular 1-ha plots.

\begin{tabular}{lcccccc}
\hline \hline & \multicolumn{5}{c}{ Overall association, $\chi \dagger$} & $\begin{array}{c}\text { Index of } \\
\text { Variable }\end{array}$ \\
\cline { 2 - 6 } & $I_{\mathrm{A}}$ & $I_{\mathrm{L}}$ & $I_{\mathrm{D}}$ & $I_{-}$ & $I_{0}$ & $\begin{array}{c}\text { aggrega- } \\
\text { tion }(I)\end{array}$ \\
\hline Sycamore maple, $I_{\mathrm{A}}$ & 1.00 & & & & & $2.10^{*}$ \\
Lobaria, $I_{\mathrm{L}}$ & $0.69^{*}$ & 1.00 & & & & $1.79^{*}$ \\
Disturbance, $I_{\mathrm{D}}$ & $0.46^{*}$ & 0.20 & 1.00 & & & $3.28^{*}$ \\
Local decrease, $I_{-}$ & $-0.31^{*}$ & $-0.44^{*}$ & $-0.23^{*}$ & 1.00 & & $1.51^{*}$ \\
No local change, $I_{0}$ & $-0.24^{*}$ & -0.13 & $-0.49^{*}$ & -0.12 & 1.00 & $1.99^{*}$ \\
Local increase, $I_{+}$ & $0.34^{*}$ & $0.28^{*}$ & $0.66^{*}$ & $-0.42^{*}$ & $-0.62^{*}$ & $2.17^{*}$ \\
\hline
\end{tabular}

$* P<0.05$.

$\dagger$ A two-tailed permutation test was used to ascertain the statistical significanc of overall association $(\chi)$ and aggregation $(I)$.

tively recently colonized and not part of a persisting lichen population.

In the alternative scenario, not all thalli were eradicated by the disturbance. Tree ring data (J. Bolli, J. M. Kalwij, H. H. Wagner, P. Cherubini, C. Scheidegger, and A. Rigling, unpublished manuscript) revealed that at least one host tree on a hill in the center of "Logged \& burnt 1871 " was not eradicated in 1871 . No data were collected in "Charcoal 1850-1900," but we assume that some remnants survived this stand-level disturbance too. We observed that especially sycamore maples in the largest dbh class often had a high abundance of L. pulmonaria, reaching as high as the crown level. Hazell and Gustafsson (1999) showed that direction of exposure had a strong impact on survival of L. pulmonaria thalli on trees retained from harvesting. This supports the alternative hypothesis that residual and colonized sycamore maples could have continued to host thalli on suitable parts of the tree. In either scenario, early colonized or remnant colonized trees could have served as a source from which nearby potential host trees were colonized. The degree to which each scenario contributes to the present distribution could be determined by estimating the historic gene flo (Sork et al. 1999) and will be addressed in a forthcoming paper (S. Werth, unpublished data).

\section{Is L. pulmonaria an indicator of ecological continuity?}

Although the patchy distribution of colonized trees, suggesting that $L$. pulmonaria was dispersal limited (Fig. 2), fell in line with the concept of ecological continuity (Norden and Appelqvist 2001), the tendency for positive spatial association of L. pulmonaria with stand-level disturbance events (Fig. 1b, Table 3) did not. Our results showed that the distribution of L. pulmonaria was clustered and that the two largest of the four lichen patches occurred in and around areas where stand-replacing disturbances occurred (Fig. 1). This suggests that disturbances may not have been severe enough or at a spatial scale large enough to cause a persisting break in the lichen population, contradicting the theory that L. pulmonaria is indicative of forest stands with an ecological continuity, sensu Rose (1976). If a high abundance of suitable substrate is more characteristic for an earlier successional stage after a stand-level disturbance event, as our results suggest, it is difficul to fin an ecological justificatio as to how this species can indicate absence of stand-replacing disturbances within the investigated area.

We identifie forest stands with a known disturbance history within a landscape that could develop into the same vegetation type under absence of anthropogenic influence (Vittoz 1998). We did so to investigate potentially persisting effects of disturbance events at define spatial and temporal scales following the critique of Rolstad et al. (2002) and Norden and Appelqvist (2001). Our sampling design was to minimize any climatic or regional gradient. We therefore only needed to take the spatial dependence of our observations into account. The spatial extent of the two stand-level disturbances may not seem as large as in previous studies, where lichen populations of undefine forest stands from different regions (Rose 1976, Boudreault et al. 2000) or different countries (Gaio-Oliveira et al. 2004) were compared. However, our stand-level disturbance events ( $\sim 31$ and 36 ha, respectively) were large enough to conform with the minimum forest stand size of $0.1-$ 30 ha (Esseen and Renhorn 1998, Hazell and Gustafsson 1999, Norden and Appelqvist 2001, Rolstad et al. 2002).

Although L. pulmonaria has been shown to suffer from permanent light damage under high light intensity (Gauslaa et al. 2001), the lichen is also light dependent; it has been shown to profi from semi-open environments and is disfavored in dark and more dense forests (Renhorn et al. 1997, Hazell and Gustafsson 1999). Our spatial analysis showed that L. pulmonaria, $I_{\mathrm{L}}$, was more associated with local increase of canopy cover and/or tree density, $I_{-}$, than with the stand-level disturbance events, $I_{\mathrm{D}}$, but that the opposite was true for sycamore maple, $I_{\mathrm{A}}$ (Table 3 ). Although the explanatory variables local increase, $I_{-}$, and stand-level disturbance events, $I_{\mathrm{D}}$, were not independent in this analysis, this indicates fewer sycamore maples in areas with local 
increase in tree density and/or tree cover than in areas with a stand-level disturbance.

Lobaria pulmonaria will be less susceptible to a decrease of air humidity (e.g., following the opening of the canopy) when precipitation is high. Our study area has a high mean annual precipitation relative to the rest of Switzerland (Spreafic 1992). Precipitation is unlikely to be limiting and present canopy cover had no significan effect on host tree density or colonization proportion (Table 2). Our results therefore suggest that L. pulmonaria may have profite from an increased availability of potential host trees, but could also have profite from improved light conditions prior to the closing up of the canopy layer.

\section{Conclusions for ecological continuity}

This paper quantifie the operational definition on the concept of ecological continuity, as suggested by Rolstad et al. (2002) and Norden and Appelqvist (2001). Since L. pulmonaria was not negatively correlated with disturbance at the forest stand level, frequency and abundance of this lichen cannot be considered as an indicator for continuity for this study area. Either processes of recolonization were so fast that colonization occurred even when trees were relatively young, or the tested indicator species was not susceptible enough to become locally and persistently extinct. This study does not dispute the value of $L$. pulmonaria as an indicator to assess forest conservation value at a landscape level; we did not compare landscapes. However, we did show that, at least in our study area, $L$. pulmonaria is less dispersal limited than would be required for an indicator of ecological continuity at a forest-stand level. Frequency and abundance of this species are therefore not the appropriate measures to indicate continuity at the spatial and temporal scales considered. Our results even suggest that disturbances could be beneficia for L pulmonaria when early successional stages result in more potential host trees and create a beneficia habitat (such as improved light conditions), provided that a viable population is within range and that spatial extent of the disturbance is not much larger than dispersal ability of the organism. This study argues that, although indicator species may be an efficien means to assess conservation value of a forest, spatially and temporally explicit knowledge of the species' life history characteristics is indispensable to prevent a possible misinterpretation of the ecological processes that the indicator aims to unravel.

\section{ACKNOWLEDGMENTS}

This project was funded by the National Centre of Competence in Research (NCCR) Plant Survival, a research program of the Swiss National Science Foundation, by the research program Forest Dynamics of the Swiss Federal Research Institute WSL, and by the Arten und BiotopschutzFlechten project of the Federal Offic of Environment, Forest and Landscape. We are grateful to S. Knol and A. Y. van Zonneveld for fiel assistance, to A. Golay, R. Meylan, B. Pichon, and E. Treboux (all of the Forest Service of the Can- ton of Vaud, Switzerland) for fiel access, to S. Werth for sharing unpublished data, and to J. J. Kalwij for help with literature access. We profite from suggestions by J.-C. Walser, S. E. Hoebee, and O. Wildi.

\section{Literature Cited}

Barkman, J. J. 1958. Phytosociology and ecology of cryptogamic epiphytes: including a taxonomic survey and description of their vegetation units in Europe. Van Gorcum, Assen, The Netherlands.

Boudreault, C., S. Gauthier, and Y. Bergeron. 2000. Epiphytic lichens and bryophytes on Populus tremuloides along a chronosequence in the southwestern boreal forest of Quebec, Canada. Bryologist 103:725-738.

Caro, T. M., and G. O'Doherty. 1999. On the use of surrogate species in conservation biology. Conservation Biology 13 : 805-814.

Denison, W. C. 2003. Apothecia and ascospores of Lobaria oregana and Lobaria pulmonaria investigated. Mycologia 95:513-518.

Dutilleul, P. 1993. Modifying the $t$ test for assessing the correlation between two spatial processes. Biometrics 49:305314.

ESRI. 2002. ArcGIS 8.3. Environmental Systems Research Institute, Redlands, California, USA.

Esseen, P. A., and K. E. Renhorn. 1998. Edge effects on an epiphytic lichen in fragmented forests. Conservation Biology 12:1307-1317.

Gaio-Oliveira, G., L. Dahlman, C. Maguas, and K. Palmqvist. 2004. Growth in relation to microclimatic conditions and physiological characteristics of four Lobaria pulmonaria populations in two contrasting habitats. Ecography 27:1328.

Gauslaa, Y. 1994. Lobaria pulmonaria, an indicator of species-rich forest of long ecological continuity. Blyttia 52: 119-128.

Gauslaa, Y., M. Ohlson, K. A. Solhaug, W. Bilger, and L. Nybakken. 2001. Aspect-dependent high-irradiance damage in two transplanted foliose forest lichens, Lobaria pulmonaria and Parmelia sulcata. Canadian Journal of Forest Research-RevuCanadienne de Recherche Forestiere 31: 1639-1649.

Gauslaa, Y., and K. A. Solhaug. 1996. Differences in the susceptibility to light stress between epiphytic lichens of ancient and young boreal forest stands. Functional Ecology 10:344-354.

Gillet, F., and J. D. Gallandat. 1996. Wooded pastures of the Jura mountains. Pages 37-53 in M. Étienne, editor. Western European silvopastoral systems. INRA editions. Institute National de la Recherche Agronomique, Paris, France.

Gu, W. D., M. Kuusinen, T. Konttinen, and I. Hanski. 2001. Spatial pattern in the occurrence of the lichen Lobaria pulmonaria in managed and virgin boreal forests. Ecography 24:139-150.

Gustafsson, L., and I. Eriksson. 1995. Factors of importance for the epiphytic vegetation of aspen Populus tremula with special emphasis on bark chemistry and soil chemistry. Journal of Applied Ecology 32:412-424.

Harper, K. A., and S. E. Macdonald. 2002. Structure and composition of edges next to regenerating clear-cuts in mixed-wood boreal forest. Journal of Vegetation Science 13:535-546.

Hazell, P., and L. Gustafsson. 1999. Retention of trees at fina harvest-evaluation a conservation technique using epiphytic bryophyte and lichen transplants. Biological Conservation 90:133-142.

Hazell, P., O. Kellner, H. Rydin, and L. Gustafsson. 1998. Presence and abundance of four epiphytic bryophytes in relation to density of aspen (Populus tremula) and other stand characteristics. Forest Ecology and Management 107: $147-158$. 
Hedenas, H., and L. Ericson. 2003. Response of epiphytic lichens on Populus tremula in a selective cutting experiment. Ecological Applications 13:1124-1134.

Hendrickson, O. 2003. Old-growth forests: data gaps and challenges. Forestry Chronicle 79:645-651.

Hilmo, O. 2002. Growth and morphological response of oldforest lichens transplanted into a young and an old Picea abies forest. Ecography 25:329-335.

Johansson, P., and J. Ehrlen. 2003. Influenc of habitat quantity, quality and isolation on the distribution and abundance of two epiphytic lichens. Journal of Ecology 91:213-221.

Johnston, K., J. M. Ver Hoef, and K. Krivoruchko. 2001. Using ArcGIS Geostatistical Analyst. ESRI Press, Redlands, California, USA.

Kuusinen, M. 1996. Cyanobacterial macrolichens on Populus tremula as indicators of forest continuity in Finland. Biological Conservation 75:43-49.

Lesica, P., B. McCune, S. V. Cooper, and W. S. Hong. 1991. Differences in lichen and bryophyte communities between old-growth and managed 2nd-growth forests in the Swan Valley, Montana. Canadian Journal of Botany-Revue Canadienne de Botanique 69:1745-1755.

Levin, S. A., H. C. Muller-Landau, R. Nathan, and J. Chave. 2003. The ecology and evolution of seed dispersal: a theoretical perspective. Annual Review of Ecology, Evolution and Systematics 34:575-604.

Lindenmayer, D. B., C. R. Margules, and D. B. Botkin. 2000. Indicators of biodiversity for ecologically sustainable forest management. Conservation Biology 14:941-950.

McCune, B., R. Rosentreter, J. M. Ponzetti, and D. C. Shaw. 2000. Epiphyte habitats in an old conifer forest in Western Washington, USA. Bryologist 103:417-427.

Nilsson, S. G., J. Hedin, and M. Niklasson. 2001. Biodiversity and its assessment in boreal and nemoral forests. Scandinavian Journal of Forest Research, Supplement 3:10-26.

Norden, B., and T. Appelqvist. 2001. Conceptual problems of ecological continuity and its bioindicators. Biodiversity and Conservation 10:779-791.

Perry, J. N., and P. M. Dixon. 2002. A new method to measure spatial association for ecological count data. Ecoscience 9: 133-141.

Perry, J. N., L. Winder, J. M. Holland, and R. D. Alston. 1999. Red-blue plots for detecting clusters in count data. Ecology Letters 2:106-113.

Peterken, G. F. 1974. A method for assessing woodland flor for conservation using indicator species. Biological Conservation 6:239-245.

Renhorn, K. E., P. A. Esseen, K. Palmqvist, and B. Sundberg. 1997. Growth and vitality of epiphytic lichens. 1. Responses to microclimate along a forest edge-interior gradient. Oecologia 109:1-9.

Riiali, A., A. Penttinen, and M. Kuusinen. 2001. Bayesian mapping of lichens growing on trees. Biometrical Journal 43:717-736.

Rochat, A. 1995. Histoire des forêts de la commune du Lieu. Pages 5-18 in A. Rochat, editor. La commune du Lieu, ses églises, ses cloches et ses forêts. Le Pelerin, Les Charbonnières, Switzerland.
Rolstad, J., I. Gjerde, V. S. Gundersen, and M. Saetersdal. 2002. Use of indicator species to assess forest continuity: a critique. Conservation Biology 16:253-257.

Rolstad, J., and E. Rolstad. 1999. Does tree age predict the occurrence and abundance of Usnea longissima in multiaged submontane Picea abies stands? Lichenologist 31: 613-625.

Rose, F. 1976. Lichenological indicators of age and environmental continuity in woodlands. Pages 279-307 in D. H. Brown, D. L. Hawksworth, and R. H. Bailey, editors. Lichenology: progress and problems. Academic Press, London, UK.

Rose, F. 1992. Temperate forest management: its effects on bryophyte and lichen flora and habitats.Pages 211-233 in J. W. Bates and A. M. Farmer, editors. Bryophytes and lichens in a changing environment.Clarendon Press, Oxford, UK.

Scheidegger, C. 1995. Early development of transplanted isidioid soredia of Lobaria pulmonaria in an endangered population. Lichenologist 27:361-374.

Scheidegger, C., S. Flachsmann, S. Zoller, and B. Frey. 1997. Naturschutzbiologie bei Flechten: Konzepte und Projekte.Pages 67-71 in H. Schöller, editor. Flechten: Geschichte, Biologie, Systematik, Oekologie, Naturschutz und kulturelle Bedeutung. Kramer, Frankfurt am Main, Germany.

Schütz, J.-P. 2002. Silvicultural tools to develop irregular and diverse forest structures. Forestry 75:329-337.

Selva, S. B. 1994. Lichen diversity and stand continuity in the northern hardwoods and spruce-fi forests of northern New England and western New Brunswick. Bryologist 97: 424-429.

Sillett, S. C., B. McCune, J. E. Peck, T. R. Rambo, and A. Ruchty. 2000. Dispersal limitations of epiphytic lichens result in species dependent on old-growth forests. Ecological Applications 10:789-799.

Sork, V. L., J. Nason, D. R. Campbell, and J. F. Fernandez. 1999. Landscape approaches to historical and contemporary gene flo in plants. Trends in Ecology and Evolution 14:219-224.

Spreafico M. 1992. Hydrological atlas of Switzerland. Landeshydrologie und -geologie, Berne, Switzerland.

SPSS. 2003. SPSS for Windows. Version 12.0. SPSS, Chicago, Illinois, USA.

Stofer, S., C. Scheidegger, M. Dietrich, M. Frei, U. Groner, C. Keller, I. Roth, F. Sutter, and E. Zimmermann. SwissLichens. WSL, Birmensdorf, Switzerland. 〈http:// hermes.wsl.ch/didado/lichenweb.page1)

Tamhane, A. C. 1977. Multiple comparisons in model I: oneway ANOVA with unequal variances. Communications in Statistics-Theory and Methods A6:15-32.

Underwood, A. J. 1997. Experiments in ecology. Cambridge University Press, Cambridge, UK.

Vittoz, P. 1998. Flore et végétation du Parc jurassien vaudois: typologie, écologie et dynamique des milieux. Université de Lausanne, Switzerland.

Walser, J. C. 2004. Molecular evidence for limited dispersal of vegetative propagules in the epiphytic lichen Lobaria pulmonaria. American Journal of Botany 91:1273-1276. 


\section{ERRATUM}

In the recent paper by J. M. Kalwij, H. H. Wagner, and C. Scheidegger (2005), "Effects of stand-level disturbances on the spatial distribution of a lichen indicator," Ecological Applications 15(6):2015-2024, the key to the shading of the histogram bars in the bottom panel of Fig. 2 is given incorrectly in the legend. The legend should have indicated that the dark gray bars represent colonized host trees, and the light gray bars represent uncolonized host trees. 